\title{
Psychosocial working conditions and depressive disorder: disentangling effects of job control from socioeconomic status using a life-course approach
}

\author{
Annemette Coop Svane-Petersen ${ }^{1}(\mathbb{D}) \cdot$ Anders Holm $^{2}$ (D) - Hermann Burr ${ }^{3}$ (D) Elisabeth Framke ${ }^{1}$ (D) Maria Melchior ${ }^{4}$.

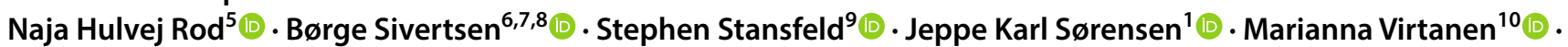 \\ Reiner Rugulies $^{1,5,11}$ (D) Ida E. H. Madsen ${ }^{1}$ (D)
}

Received: 3 May 2019 / Accepted: 3 September 2019 / Published online: 10 September 2019

(c) The Author(s) 2019

\begin{abstract}
Purpose Job control, the combination of skill discretion and decision authority, is considered a central component of the psychosocial working environment. This longitudinal study examines the relation between job control and risk of incident depressive disorder using a life-course approach.

Methods We analyze data from The Danish Work Life Course Cohort study, including all Danish individuals aged 15-30 who entered the Danish labor market during 1995-2009 and were free from depressive disorder at entry (955,573 individuals). We measured job control using a job exposure matrix. Depressive disorders were measured using information from nationwide registers of psychiatric in- and outpatient admissions. Using Cox regression models we estimated the prospective association between job control and risk of incident depressive disorders. Analyses accounted for a range of potential confounders prior to workforce entry including socioeconomic status in adolescence and parental psychiatric and somatic diagnoses prior to labor market entry, together with potential confounders in adulthood including income, education, and demographics.

Results Lower levels of past year job control were associated with a higher risk of depressive disorder after adjustment for all covariates $(\mathrm{HR}=1.27,95 \%$ CI 1.16-1.38). Results stratified by gender showed associations for both men (HR $=1.38,95 \%$ CI $1.19-$ 1.61) and women ( $\mathrm{HR}=1.19,95 \% \mathrm{CI} 1.08-1.32)$. Conclusions: Our findings suggest that the level of job control at work affects the risk of clinically diagnosed depressive disorder, and that this association is not due to confounding by socioeconomic status.
\end{abstract}

Keywords Depressive disorder $\cdot$ Psychosocial work environment $\cdot$ Life course $\cdot$ Occupational health $\cdot$ Job exposure matrix

Electronic supplementary material The online version of this article (https://doi.org/10.1007/s00127-019-01769-9) contains supplementary material, which is available to authorized users.

Ida E. H. Madsen

ihm@nfa.dk

1 National Research Centre for the Working Environment, Copenhagen, Denmark

2 Department of Sociology, University of Western Ontario, London, Canada

3 Department of Work and Health, Federal Institute for Occupational Safety and Health, Berlin, Germany

4 INSERM, Sorbonne Université, Institut Pierre Louis d'Épidémiologie et de Santé Publique, Paris, France

5 Section of Epidemiology, Department of Public Health, University of Copenhagen, Copenhagen, Denmark

6 Department of Health Promotion, Norwegian Institute of Public Health, Bergen, Norway

7 Department of Research and Innovation, Helse Fonna HF, Haugesund, Norway

8 Department of Mental Health, Norwegian University of Science and Technology (NTNU), Trondheim, Norway

9 Centre for Psychiatry, Barts and the London School of Medicine and Dentistry, Queen Mary University of London, London, UK

10 School of Educational Sciences and Psychology, University of Eastern Finland, Joensuu, Finland

11 Department of Psychology, University of Copenhagen, Copenhagen, Denmark 


\section{Introduction}

Depressive disorder is highly prevalent and causes considerable suffering for individuals affected [1, 2] as well as financial loss for employers and society [3, 4] through lost work hours, reduced work functioning and disability [5-8]. Depressive disorder is etiologically complex with multiple risk factors involving biological, environmental and psychological factors [9-12]. A growing body of research suggests that poor psychosocial working conditions increase the risk of depressive disorders [13-15]. Among the many factors characterizing the psychosocial working environment, the most widely examined factor in relation to depression is job control [13, 14], one of the two dimensions of the demand/control model [16]. Job control is a combination of the skill discretion (possibilities of development) and decision authority (influence) of a job. These aspects of work are often interrelated and thought to mutually reinforce effects of each other [17].

Theoretically, a relation between job control and depressive disorder may be explained by learned helplessness, a psychological state which has been related to the development of depressive disorder [18]. Further, Bandura suggested that lower sense of self-efficacy to exercise control increases risk of depressive disorder through unobtainable standards of self-worth and through social isolation due to a perceived inefficiency in developing rewarding social relations [19-22]. From a sociological perspective, Brown and Harris argued that the "social origins of depressive disorder" have their basis mainly in a lack of influence about important aspects of life [23]. They examined socially disadvantaged women in England and showed that certain environmental stressors outside the individuals' control, e.g., problems regarding housing, financing, husband and child, in combination with pre-existing vulnerability factors, were associated with an increased risk of depressive disorders [24].

Empirically, several studies have shown relations between job control and depressive disorder. Two recent meta-analyses found that low job control is a risk factor for depressive disorder $[13,14]$. However, the extant literature has at least five methodological limitations. First, socioeconomic status (SES) is an important confounder because job control is closely linked with SES as the level of skill discretion and decision authority are also indicators of occupational grade, a core measure of SES. Most previous studies have included only measures of adulthood socioeconomic status (SES). This is a concern, because not only adult SES but also the long-term influences of earlier life circumstances may be risk factors of depressive disorder [25-27] independently of adult SES [28]. Second, most studies have not followed individuals from the beginning of their work lives. Thus the study populations may have been affected by healthy worker selection, as the population consists of individual who remained within the workforce without developing depressive disorder for years, perhaps even decades, which in turn may yield an underestimation of the effect of job control on depressive disorder. Third, the majority of studies have been unable to account for selection of individuals with increased risk of depressive disorder into occupations with low levels of job control. A recent study of the associations between job strain, job control and risk of common mental disorder [29] found that associations were attenuated when life-course variables on psychiatric history and other confounders were used to account for such selection. Such selection has also previously been found in studies of other work environment factors and depressive disorder [30-32]. Fourth, job control has been mostly assessed only at baseline which is problematic because the effects of job control may accumulate over time, and because changes in exposure remain undetected [33]. Fifth, most studies exclusively measured job control using self-report thereby increasing the risk of reporting bias as pre-clinical symptoms of depressive disorder may affect the reporting of the working conditions $[34,35]$.

In this article, we address these limitations of the extant literature by analyzing detailed register data on risk of depressive disorder among all young Danish workers first entering the workforce. First, to minimize residual confounding by unmeasured socioeconomic circumstances, we apply a life-course approach and control for the socioeconomic gradient using several indicators of SES at different stages throughout the life course. A lifecourse approach is particularly relevant for examining the influence of SES on the risk of depressive disorder, as it takes into account long-term effects on health during childhood, adolescence and later adult life [29, 36-38]. Second, we assess job control repeatedly and examine the risk of depressive disorder associated with accumulated levels of job control across the work life. Third, we assess job control with a job exposure matrix (JEM) instead of self-report to avoid inflation of the estimated associations due to reporting bias. We published a protocol detailing the analyses before they were conducted, to avoid post hoc decision-making in the analytic process [39].

The first aim of our study was to examine the prospective association between the past year level of job control and subsequent risk of incident depressive disorder while accounting for a range of risk factors throughout the life course. The second aim was to elucidate the temporality of the association between job control and depressive disorder by distinguish past year effects from those accumulating over time. 


\section{Methods}

\section{Study population}

The study population was drawn from the register-based open cohort DAWCO. DAWCO comprises all young individuals aged 15-30 who lived in Denmark and had gainful employment as their main source of income according to Danish registers [40] for at least 1 year during the years 1995-2009, and who had not previously been registered as mainly gainfully employed $(N=979,257)$. The present study population consisted of 955,573 individuals excluding those DAWCO individuals who emigrated $(n=13,087)$, died $(n=71)$, or received disability pension $(n=361)$ in their year of entry, has missing data on gender and migrant status $(n=5176)$, or had a clinical diagnosis of depressive disorder prior to workforce entry $(n=4989)$. The individuals were followed annually from year of entry to end of follow-up in 2010 yielding a total of $6,991,811$ person years. The relatively high levels of missing parental education data (maternal education $37.7 \%$ and paternal education $47.2 \%$ in year of entry) were related to the age of the cohort members as parental linkage to education could not be obtained prior to 1980 , and to migration status of the cohort members' parents as information on parental education achieved outside Denmark could not be obtained prior to migration to Denmark. We retained individuals with missing parental data in the cohort to ensure cohort completeness, but accounted for missing data in the analyses.

\section{Measures}

\section{Exposure variable: job control}

The predicted level of job control was assessed using a Job Exposure Matrix (JEM). JEMs were first used in work environment studies in the 1980s [41], and recently, several studies on the development or application of JEMs have been published from Finland, France, the Netherlands, Denmark and Germany [42-47]. In countries such as Denmark with population based administrative registers, JEMs enable studies of associations between work environment and health in nationwide cohorts. In the present study, the JEM was based on five self-reported items from The Danish Work Environment Cohort Study [48, 49] in years 2000 and 2005. Four items originated from the Copenhagen Psychosocial Questionnaire (COPSPQ) [50], whereas the fifth item had non-COPSOQ response options [51]. The items used to measure job control can be found in Online Resource Table S1. Weighing each item equally, we calculated a scale value ranging from 1 to 5 as the mean of item scores. To ease interpretation, we reversed the original scale so that higher scores indicate lower job control. Using the survey data, we estimated the predicted level of control as a function of job group, gender, age and year of data collection. Subsequently, these JEM-values for predicted level of control were assigned to the register-based population. Occupational groups were classified according to the Danish version of the ISCO- 88 classification (DISCO-88). The intraclass correlation coefficient (ICC) for the JEM was 0.30 which is satisfactory compared to other JEM-based exposures for psychosocial work environment factors [47]. The occupations with the lowest and highest levels of job control are presented in Table S2. The validity of the JEM is supported by its distribution, as the lowest levels of job control were primarily in occupations of lower occupational position (as indicated by 1-digit DISCO-groups 8-9), and the highest levels of job control were primarily in occupations of higher position (DISCO-groups 1-2). For more information on the development of the JEM, see Madsen 2018 [39]. To improve comparability to previous research, we further estimated the association categorically in terms of a high exposure group and a low exposure group defined by median split.

To measure accumulated level of job control we added annual JEM-values for each individual across the years in the cohort. To further explore the accumulated level of job control, we constructed a measure for the proportion of previous annual measures with low level of job control (defined by median split) that was further categorized into four groups with cut points at $5 \%, 25 \%$ and $75 \%$. The correlation between past year job control and accumulated level of job control was moderate with a Pearson's correlation coefficient of 0.29. Table $\mathrm{S} 3$ shows the distribution of individuals with low level of job control in the past year in relation to the proportions of cumulative exposure. Results show that a large proportion of individuals who have low job control in the past year also had low job control in previous years. All measures for job control were included as time-varying variables in the statistical models.

\section{Outcome: depressive disorder}

Depressive disorder was assessed using data from The Psychiatric Central Research Register [52] (years 1969-1994) and The National Patient Register [53] (years 1995-2010). Combined, the two registers encompass all psychiatric inpatient treatments since 1969 and from 1995 onwards include both in- and outpatient treatments [52]. We defined depressive disorder as a main diagnosis from in- or outpatient treatment of 296.0, 296.2, 298.0, 300.4 from ICD8 (for the years 1969-1993) and F32 or F33 from ICD10 (for the years 
1994-2010). In the current analysis we excluded individuals diagnosed with depressive disorder prior to workforce entry further encompassing the diagnoses 308.02 (ICD8) and F92.0 (ICD10) for depressive disorder in childhood or adolescence.

\section{Possible confounders}

Life-course SES We used several register-based indicators of SES $[40,54,55]$ at different stages throughout the life course with each indicator emphasizing different aspects of social stratification. Adulthood SES was measured with income [36] included from year $t$ and categorized in deciles, and educational attainment [36] categorized in six categories according to the International Standard Classification of Education (ISCED) [56]: primary and lower secondary (ISCED levels 1 and 2), upper secondary (ISCED level 3), short cycle tertiary (ISCED level 5), bachelor or equivalent (ISCED level 6), master, doctoral (ISCED level 7), and a category for missing data, in year $t-1$. We used information on education in year $t-1$ to ensure the correct temporal order between education and job control for confounding, i.e., that the measure for education preceded the exposure measurement, and to avoid multi-collinearity in the model due to certain jobs possibly having no variation in educational level.

We included variables on SES in adolescence drawn from Danish registers [40,54] because (i) studies have found SES in early life to be a risk factor for depressive disorder [28] and (ii) SES is a potential confounder as it has also been associated with labor force participation in adulthood [57, 58] that attenuates the association between work environment factors and labor market exit [59]. In line with previous studies [60, 61], variables measuring adolescence SES were maternal and paternal education categorized in five groups according to ISCED, and occupational position categorized in two groups (employed, unemployed/outside the labor force, and a category for missing information) following the guidelines set by ILO [62]. Both variables were measured when the cohort member was 15 years old, but in cases of missing information we retrieved data back to birth or up to age 20. Parental data linkage was only available from 1980 and onwards leaving this information unavailable for 9.8\% of individuals for maternal data and $11.1 \%$ for paternal data. In the analysis we adjusted for missing parental data by dummy variables. Variables on adolescence SES were included as time-invariant in the analyses while adult SES were time varying.

Life-course risk factors for depressive disorder: parental psychiatric and somatic diagnoses Additionally, we included variables on all parental ICD10 psychiatric diagnoses prior to the cohort member entering the workforce because pre- vious research shows that parental psychiatric disorder is a risk factor for depressive disorder [63-65]. We further included variables on parental somatic diagnoses of heart disease and cancer prior to the cohort member entered the workforce because previous research suggests that children of ill parents have increased vulnerability to depressive disorder [66, 67]. Variables were drawn from The National Patient Register [53] and The Psychiatric Central Research Register [52] and included as time-invariant in the analyses.

\section{Other variables}

We controlled for factors that, based on previous literature, were likely to be risk factors for depressive disorder [2, 68, 69] and be unequally distributed across occupational groups. These register-based variables [40, 70] included gender, age, cohabitation (single, cohabiting), ethnicity (Danish, immigrant/descendant of immigrant), number of children in the household, employment status (employed, self-employed, unemployed, studying), years of non-employment and years of work experience. Gender and ethnicity were included as time-invariant in the analyses, while the remaining variables were time-variant.

\section{Analysis}

For all analyses, we used the SAS 9.4 program package. We used Cox proportional hazard models with time-dependent covariates and calendar time as underlying time axis to estimate the association between level of job control and subsequent risk of incident depressive disorder [71]. We included both past year level of job control at time $t$ and the accumulated level of job control at time $t$ and all previous years concurrently. We analyzed data with a 1-year time lag and related exposure to job control in year $t$ to outcome during year $t+1$. We followed individuals from their year of workforce entry until the first diagnosis of depressive disorder or any of the absorbing states: death, emigration or award of disability pension, or end of follow-up 31 December 2010, whichever came first. We applied logarithmic transformation $(\log 2)$ of the JEM estimate for exposure (the predicted level of job control), so that the estimated parameters could be interpreted as the risk associated with a halving of the level of job control. This transformation was applied to ease comparability of the results of the present study to those studies examining effects of job control using other measures.

In the main analysis (Model 1), we adjusted for gender, age, cohabitation status, ethnicity, number of children in the household, employment status, years of non-employment, years of work experience, income, SES in adolescence (parental education and occupational position) and parental psychiatric and somatic diagnoses. Because education is particularly closely linked with job control, we further 
adjusted for highest level of education in time $t-1$ separately in Model 2.

\section{Sensitivity analyses}

To assess the robustness of the findings, we ran models stratified by gender, migrant status, educational level and industrial sectors and examined the association in terms of a high exposure group and a low exposure group defined by median split. Further, to assess the influence of the included lifecourse variables preceding workforce entry on the estimated association between job control and depressive disorder, we conducted a post hoc sensitivity analysis, in which we omitted adjustment for these factors and compared results from these models to those from the main analysis. We also ran models excluding individuals diagnosed with any ICD10 diagnosis of psychiatric morbidity before baseline and repeated the main analysis with three alternative definitions of accumulated exposure: (1) number of previous years with low job control; (2) proportions of previous years with low job control; (3) proportion of previous years with low job control measured in categories. Finally, to assess whether the estimated association between job control and depressive disorder could be explained by other working conditions, we ran a model further adjusting for psychological demands, emotional demands, physical work demands, and risk of violence at work, all measured by job exposure matrices.

\section{Results}

\section{Describing the population}

Table 1 shows characteristics of the population at year of cohort entry. Men and women were represented equally and the average age was 20.2. The majority of individuals were born in Denmark (84.9\%), cohabiting (64.2\%), and had primary or lower secondary education as the highest level of education (71.9\%). Regarding adolescent SES, most parents of the cohort members had upper secondary education as their highest level of education $(25.0 \%$ and $27.0 \%)$ and were employed (maternal employment $64.4 \%$, paternal employment $73.8 \%$ ), when the cohort members were 15 years old.

\section{Level of job control and depressive disorder}

We identified 16,153 individuals with incident hospitaltreated depressive disorder during follow-up. Table 2 shows the association between job control and depressive disorder. Individuals working in occupations with lower levels of job control in the past year had a higher risk of depressive disor$\operatorname{der}(\mathrm{HR}=1.62,95 \%$ CI 1.49-1.76) compared to individuals in jobs with higher levels of job control after accounting for
Table 1 Characteristics of the study population in their year of entry into the workforce

\begin{tabular}{|c|c|c|c|}
\hline & $N$ & $\%$ & Mean \\
\hline Total sample & 955,573 & 100 & \\
\hline \multicolumn{4}{|l|}{ Gender } \\
\hline Men & 484,422 & 50.7 & \\
\hline Women & 471,151 & 49.3 & \\
\hline Age & & & 20.2 \\
\hline $15-17$ & 103,410 & 10.8 & \\
\hline $18-19$ & 379,211 & 39.7 & \\
\hline $20-24$ & 378,299 & 39.6 & \\
\hline $25-30$ & 94,653 & 9.9 & \\
\hline \multicolumn{4}{|l|}{ Cohabitation } \\
\hline Yes & 613,502 & 64.2 & \\
\hline No & 298,507 & 31.2 & \\
\hline Unknown & 43,564 & 4.6 & \\
\hline \multicolumn{4}{|l|}{ Ethnicity } \\
\hline Danish & 811,622 & 84.9 & \\
\hline Non-Danish & 143,951 & 15.1 & \\
\hline \multicolumn{4}{|l|}{ Children in the household } \\
\hline 0 & 286,040 & 29.9 & \\
\hline$\geq 1$ & 669,533 & 70.1 & \\
\hline \multicolumn{4}{|l|}{ Education } \\
\hline Primary or lower secondary & 686,791 & 71.9 & \\
\hline Upper secondary & 172,169 & 18.0 & \\
\hline Short cycle tertiary & 4319 & 0.5 & \\
\hline Bachelor or equivalent & 13,319 & 1.4 & \\
\hline Master or equivalent & 5389 & 0.6 & \\
\hline Doctoral or equivalent & 13 & $<0.1$ & \\
\hline Not classified/unknown & 73,573 & 7.7 & \\
\hline \multicolumn{4}{|l|}{ Maternal psychiatric diagnosis } \\
\hline Yes & 62,543 & 6.6 & \\
\hline No & 893,030 & 93.5 & \\
\hline \multicolumn{4}{|l|}{ Paternal psychiatric diagnosis } \\
\hline Yes & 57,733 & 6.0 & \\
\hline No & 897,840 & 94.0 & \\
\hline \multicolumn{4}{|l|}{ Maternal somatic diagnosis } \\
\hline Yes & 40,617 & 4.3 & \\
\hline No & 821,176 & 85.9 & \\
\hline \multicolumn{4}{|l|}{ Paternal somatic diagnosis } \\
\hline Yes & 55,373 & 5.8 & \\
\hline No & 794,235 & 83.1 & \\
\hline \multicolumn{4}{|l|}{ Maternal education } \\
\hline Primary or lower secondary & 207,277 & 21.7 & \\
\hline Upper secondary & 238,304 & 25.0 & \\
\hline Short cycle tertiary & 16,331 & 1.7 & \\
\hline Bachelor or equivalent & 111,198 & 11.6 & \\
\hline Master or doctoral & 22,624 & 2.4 & \\
\hline Not classified/unknown & 359,839 & 37.7 & \\
\hline \multicolumn{4}{|l|}{ Paternal education } \\
\hline Primary or lower secondary & 123,473 & 13.0 & \\
\hline Upper secondary & 258,260 & 27.0 & \\
\hline
\end{tabular}


Table 1 (continued)

\begin{tabular}{lrrr}
\hline & \multicolumn{1}{l}{ M } & \multicolumn{1}{l}{ Mean } \\
\hline Short cycle tertiary & 22,091 & 2.3 & \\
Bachelor or equivalent & 54,981 & 5.8 & \\
Master or doctoral & 45,357 & 4.8 & \\
Not classified/unknown & 451,411 & 47.2 & \\
Maternal occupational position & & & \\
Employed & 653,987 & 64.4 \\
Non-employed & 192,581 & 20.1 \\
Unknown & 109,005 & 11.4 \\
Paternal occupational position & & \\
Employed & 705,361 & 73.8 \\
Non-employed & 122,213 & 12.8 \\
Unknown & 127,999 & 13.4 \\
Missing maternal data & 93,780 & 9.8 \\
Missing paternal data & 105,965 & 11.1 \\
\hline
\end{tabular}

accumulated levels of job control, life-course SES (excluding education) and the other covariates (Table 2, Model 1). The association was attenuated, but remained statistically significant after further adjustment for highest level of education ( $\mathrm{HR}=1.27,95 \%$ CI 1.16-1.38) (Table 2, Model 2).

There was no statistically significant association between accumulated level of job control and depressive disorder after accounting for past year level of job control and covariates (Table 2, Model 1). After accounting for educational level in Model 2, this association remained statistically non-significant.

To improve comparability to previous research, we estimated the association in terms of a dichotomized variable defining groups with high and low job control using median split (Table 2). We found a hazard ratio for depressive disorder of 1.15 (95\% CI 1.11-1.20) for employees with the low past year job control compared to employees with high job control after adjusting for accumulated level of job control and covariates (Table 2, Model 1). The association attenuated but remained statistically significant after adjusting for educational level $(\mathrm{HR}=1.07,95 \%$ CI 1.03-1.12) (Table 2, Model 1).

\section{Sensitivity analyses}

In the fully adjusted model, analysis stratified by gender (Table 3) showed that the association between past year level of job control and risk of incident depressive disorder was similar in men (HR 1.38, 95\% CI 1.19-1.61) and women (HR 1.19, 95\% CI 1.08-1.32). Accumulated level of job control was statistically significant only for men (HR 1.41, 95\% CI 1.05-1.89). Analyses stratified by ethnicity (Table 3) showed a statistically significant association between past year level of job control and depressive disorder in individuals of Danish ethnicity (HR 1.29, 95\% CI 1.18-1.41), but no association in immigrants/descendants of immigrants (HR 0.91, 95\% CI 0.70-1.18) in the fully adjusted model. However, accumulated exposure was statistically significantly associated with depressive disorder in immigrants/ descendants of immigrants (HR 2.05, 95\% CI 1.03-4.09), but not in ethnic Danes.

Figure 1 shows the associations for level of job control and risk of depressive within strata of educational level and Fig. 2 shows the association within industries. The detailed results are presented in Online Resource Tables S4 and S5. When stratifying by educational level the association between past year level of job control and

Table 2 Risk of depressive disorder in relation to past year level of job control

\begin{tabular}{|c|c|c|c|c|c|c|c|c|c|}
\hline & \multirow[t]{2}{*}{ PY } & \multirow[t]{2}{*}{ Cases } & \multirow{2}{*}{$\begin{array}{l}\text { Cases per } \\
10.000 \\
\text { PY }\end{array}$} & \multicolumn{3}{|l|}{ Model 1} & \multicolumn{3}{|l|}{ Model 2} \\
\hline & & & & Hazard ratio & $\begin{array}{l}95 \% \\
\text { confidence } \\
\text { interval }\end{array}$ & $P$ value & Hazard ratio & $\begin{array}{l}95 \% \\
\text { confidence } \\
\text { interval }\end{array}$ & $P$ value \\
\hline $\begin{array}{l}\text { Past year level of job control, per } \\
\text { halved level }\end{array}$ & $6,991,811$ & 16,148 & 23 & 1.62 & $1.49-1.76$ & $<0.001$ & 1.27 & $1.16-1.38$ & $<0.001$ \\
\hline \multicolumn{9}{|l|}{ Past year job control, dichotomized } & $<0.001$ \\
\hline Low & $4,109,574$ & 11,020 & 27 & 1.15 & $1.11-1.20$ & $<0.001$ & 1.07 & $1.03-1.12$ & $<0.001$ \\
\hline High & $2,882,238$ & 5,128 & 18 & 1.00 & Ref. & & 1.00 & Ref. & \\
\hline $\begin{array}{l}\text { Accumulated level of job control, } \\
\text { per halved level }\end{array}$ & $6,991,811$ & 16,148 & 23 & 1.20 & $1.00-1.43$ & 0.053 & 1.19 & $1.00-1.42$ & 0.053 \\
\hline
\end{tabular}

Associations for past year job control and accumulated job control are included in the same models (mutually adjusted)

Higher values on the job control scale indicate lower job control

Model 1 is adjusted for gender, age, cohabitation, ethnicity, number of children, employment status, years of non-employment, years of work experience, income, maternal and paternal psychiatric and somatic diagnoses, maternal and paternal education and occupational position

Model 2: estimates are additionally adjusted for highest level of education

$P Y$ person years 
Table 3 Risk of depressive disorder in relation to past year level of job control stratified by gender and ethnicity

\begin{tabular}{|c|c|c|c|c|c|c|c|c|c|}
\hline & \multirow[t]{2}{*}{ PY } & \multirow[t]{2}{*}{ Cases } & \multirow{2}{*}{$\begin{array}{l}\text { Cases per } \\
10.000 \\
\text { PY }\end{array}$} & \multicolumn{3}{|l|}{ Model 1} & \multicolumn{3}{|l|}{ Model 2} \\
\hline & & & & Hazard ratio & $\begin{array}{l}95 \% \\
\text { confidence } \\
\text { interval }\end{array}$ & $P$ value & Hazard ratio & $\begin{array}{l}95 \% \\
\text { confidence } \\
\text { interval }\end{array}$ & $P$ value \\
\hline Men & $3,557,930$ & 5378 & 15 & & & & & & \\
\hline $\begin{array}{l}\text { Past year level of job control, per } \\
\text { halved level }\end{array}$ & & & & 1.79 & $1.54-2.07$ & $<0.001$ & 1.38 & $1.19-1.61$ & $<0.001$ \\
\hline $\begin{array}{l}\text { Accumulated level of job control, } \\
\text { per halved level }\end{array}$ & & & & 1.52 & $1.12-2.05$ & 0.007 & 1.41 & $1.05-1.89$ & 0.023 \\
\hline Women & $3,433,882$ & 10,770 & 31 & & & & & & \\
\hline $\begin{array}{l}\text { Past year level of job control, per } \\
\text { halved level }\end{array}$ & & & & 1.49 & $1.34-1.64$ & $<0.001$ & 1.19 & $1.08-1.32$ & 0.0008 \\
\hline $\begin{array}{l}\text { Accumulated level of job control, } \\
\text { per halved level }\end{array}$ & & & & 1.12 & $0.89-1.41$ & 0.334 & 1.16 & $0.93-1.46$ & 0.1855 \\
\hline Danish ethnicity & $6,227,382$ & 14,531 & 23 & & & & & & \\
\hline $\begin{array}{l}\text { Past year level of job control, per } \\
\text { halved level }\end{array}$ & & & & 1.68 & $1.54-1.83$ & $<0.001$ & 1.29 & $1.18-1.41$ & $<0.001$ \\
\hline $\begin{array}{l}\text { Accumulated level of job control, } \\
\text { per halved level }\end{array}$ & & & & 1.07 & $0.89-1.29$ & 0.466 & 1.12 & $0.93-1.34$ & 0.241 \\
\hline Non-Danish ethnicity & 764,430 & 1617 & 21 & & & & & & \\
\hline $\begin{array}{l}\text { Past year level of job control, per } \\
\text { halved level }\end{array}$ & & & & 0.99 & $0.77-1.28$ & 0.967 & 0.91 & $0.70-1.18$ & 0.595 \\
\hline $\begin{array}{l}\text { Accumulated level of job control, } \\
\text { per halved level }\end{array}$ & & & & 2.41 & $1.19-4.89$ & 0.014 & 2.05 & $1.03-4.09$ & 0.041 \\
\hline
\end{tabular}

Associations for past year job control and accumulated job control are included in the same models (mutually adjusted)

Model 1: estimates are adjusted for gender, age, cohabitation, ethnicity, number of children, employment status, years of non-employment, years of work experience, income, education, maternal and paternal psychiatric and somatic diagnoses, maternal and paternal education and occupational position

Model 2: estimates are additionally adjusted for highest level of education

$P Y$ person years

\begin{tabular}{|c|c|c|c|}
\hline \multicolumn{4}{|l|}{ Primary or lower secondary } \\
\hline Past year level of job control & $2,532,115$ & 7,675 & 30 \\
\hline \multicolumn{4}{|l|}{ Upper secondary } \\
\hline Past year level of job control & $3,234,617$ & 7,675 & 24 \\
\hline \multicolumn{4}{|l|}{ Short cycle tertiary } \\
\hline Past year level of job control & 194,981 & 273 & 14 \\
\hline \multicolumn{4}{|l|}{ Bachelor or equivalent } \\
\hline Past year level of job control & 610,136 & 1,028 & 17 \\
\hline \multicolumn{4}{|l|}{ Master or equivalent } \\
\hline Past year level of job control & 260,469 & 264 & 10 \\
\hline \multicolumn{4}{|l|}{ Not classified / Unknown } \\
\hline Past year level of job control & 150,981 & 275 & 18 \\
\hline
\end{tabular}
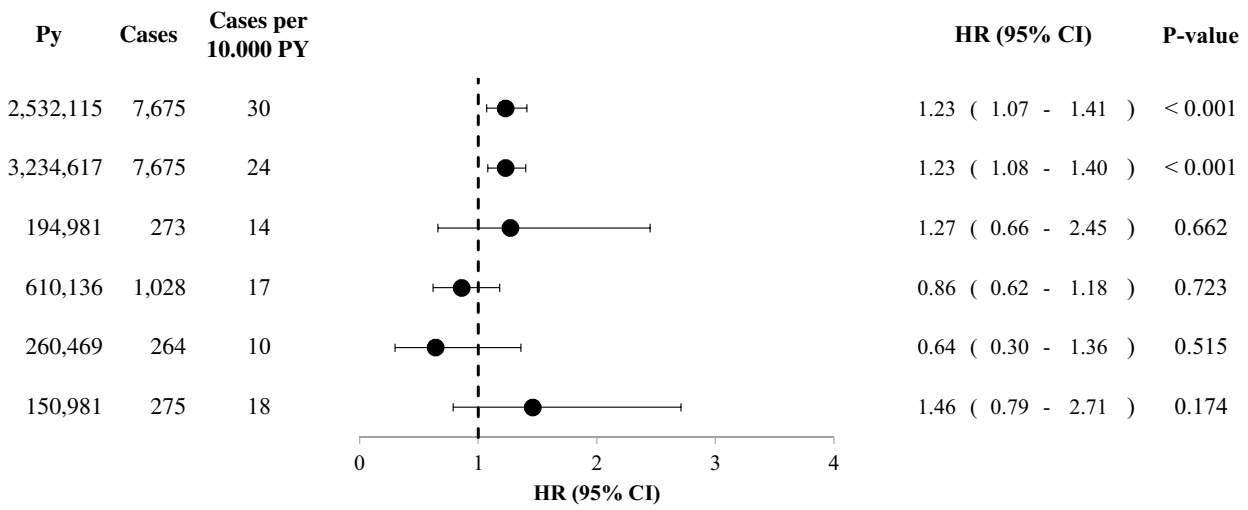

Fig. 1 Depressive disorder in relation to past year level of job control within subgroups of educational level

depressive disorder were similar with an elevated risk in the two lowest educational groups; primary or lower secondary education. For higher levels the association changed directions but were statistically non-significant.
In the fully adjusted model, the association was statistically non-significant in most industries (Online Resource Table S5, Model 2) and accumulated exposure showed 


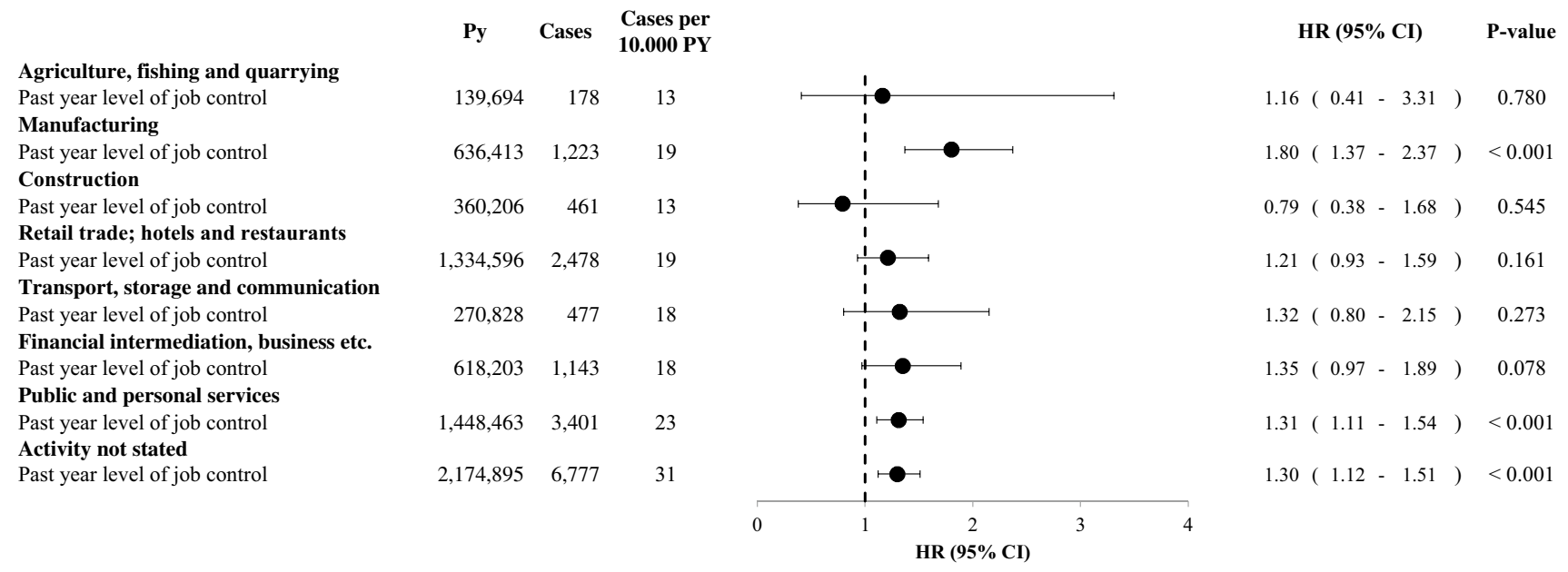

Fig. 2 Depressive disorder in relation to past year level of job control within industries

a non-statistically significant association with depressive disorder in all industries.

\section{Supplementary analyses}

Online Resource Table S6 shows the estimates for selected covariates. In the fully adjusted model, the life-course variables pre-existing labor market entry (parental education and occupational status, parental psychiatric diagnoses and somatic diagnoses of heart disease) predicted risk of depressive disorder. When we omitted adjustment for these factors (Online Resource Table S7) we found similar associations between past year level of job control and depressive disorder with hazard ratios of 1.73 (Model 1) and 1.29 (Model 2).

Regarding past year level of job control, results from the analysis excluding individuals diagnosed with any psychiatric diagnoses before baseline were similar to the main analysis, while accumulated exposure became statistically significantly associated with risk of depressive disorder (Online Resource Table S8). Results from the analysis on alternative definitions of accumulated exposure showed no statistically significant association with risk of depressive disorder (Online Resource Tables S9-S11). When we adjusted for other working conditions (psychological demands, emotional demands, physical work demands, and risk of violence at work), the results were similar to those from the main analysis, with hazard ratios of 1.77 (95\% CI 1.57-2.00) for past year job control and 1.20 (95\% CI 1.00-1.4) for accumulated level of job control.

\section{Discussion}

We found that employment in occupations characterized by lower levels of job control is associated with a higher risk of first-time hospital-diagnosed depressive disorder. This association was not explained by known risk factors for depressive disorder including gender and life-course variables on SES in adulthood, SES in adolescence, and parental psychiatric and somatic diagnoses prior to entering the labor market. The association was attenuated but remained statistically significant after further adjustment for educational attainment (Aim 1). The main analysis showed no consistent association between accumulated levels of job control and depressive disorder (Aim 2). Associations for past year job control were similar in men and women. However, associations were education specific and statistically non-significant in most industries after additional adjustment for highest level of education.

\section{Relations to previous literature}

Previously, the effects of job control accumulated during the working life on cardiovascular mortality, have been examined by Johnson et al. [72]. Our study is the first, however, to apply a life-course approach to disentangle the association of job control and depressive disorder from effects of SES. We followed individuals from the beginning of their working lives and accounted for potential risk factors for depressive disorder pre-existing labor market entry, and selection into specific occupational groups. Our findings suggest an effect of job control on depressive disorder. Possible mechanisms that have all been related to the etiology of depressive disorder are learned helplessness [18], low sense of self-efficacy [19-22], and lack of influence about important aspects of life [23]. Our findings extend previous studies associating job control with indicators of depressive disorder [13] and depressive symptoms [14]. We found that the life-course variables of risk factors for depressive disorder pre-existing workforce entry were independent risk factors for depressive 
disorder. However, when these factors were omitted from the analysis, results for job control were similar to those of the main analysis. This is in line with findings from a recent study investigating the association between job control and other psychosocial work environment factors and common mental disorders in a life-course perspective [29]. This study found that the association between job control and common mental disorders was clearly attenuated by risk factors for common mental disorders in childhood and early youth but remained statistically significant. Further, a twin study by Theorell et al. [73] showed that biological trait factors, which could predispose individuals simultaneously to both reporting low job control and develop depression, are unlikely to be a major bias of the estimated associations between job control and depression. These findings all suggest that any bias due to the selection of individuals with higher risk of depressive disorder into occupations with low job control has likely been only a minor issue in previous studies on the topic, and point to the importance of intervening to increase job control levels, as this could potentially prevent some cases of depression.

Research regarding workplace interventions to increase levels of job control suggests that such interventions may be associated with better employee sleep quality, improved mental health and reduced levels of depressive symptoms [74-76]. There is also evidence suggesting positive organizational effects of job control interventions, in terms of increased productivity and decreased sickness absence [77]. However, more high-quality studies and replication studies are needed to establish which interventions are effective under which circumstances [77].

\section{Accumulation of exposure}

Our results concerning the association between accumulated job control and depressive disorder remain inconclusive. We found no association in the main analyses, but there were some indication of accumulation in supplementary analyses within specific subgroups. To the best of our knowledge our study is the first to examine accumulated levels of job control as previous studies have only included exposure at one point in time. Therefore, further research is needed to conclude firmly on the subject.

\section{Differences in the associations between job control and depressive disorder by educational level}

Stratification by educational level showed that the association between past year level of job control and depressive disorder was primarily seen in lower educational levels. There is a strong correlation between education and job control, with increasing educational levels associated with higher job control $[78,79]$. Some studies have suggested that there are non-linear associations between influence at work and well-being, and that more influence may no longer be associated with better well-being at the highest levels [80]. It is possible, that such non-linearity may explain that the associations in the present study were limited to lower educational levels. Furthermore, the lack of association in individuals with higher educational levels may be related to misclassification of our outcome, as individuals with higher education may have more financial resources and may be more likely to enter private psychiatric or psychological treatment for any mental health problems, and such treatments are not included in the registers applied to measure depression in the present study [52].

Alternatively, the stronger association between job control and depressive disorders in lower SES groups may be related to sample characteristics as the present study follows individuals in their first years on the Danish labor market, before achieving their highest level of education. Therefore, to firmly establish whether or not job control is associated with depressive disorder also in individuals with higher educational levels, the study design would need to encompass middle aged and older employees as well.

\section{Strengths and limitations}

A considerable strength of this study is its ability to minimize residual confounding by accounting for unmeasured risk factors prior to labor market entry. In particular, we adjusted for socioeconomic circumstances by multiple SES indicators measured across the life course to comprehensively account for the socioeconomic gradient in the risk of depressive disorder. Additional strengths are the nationwide cohort of young workers and the ability to follow individuals from the beginning of their work lives in order to avoid downwards biased estimates due to healthy worker selection.

Some limitations should be noted. First, job control was assessed using a JEM-based on job group, gender and age. Although the JEM showed relatively good validity, indicated by an ICC of 0.30 and higher job control scores in individuals of high SES, the associations between job control and onset of depressive disorder estimated in this paper should be interpreted in relation to occupational group, i.e., the risk of depressive disorder in employees in occupations with lower job control compared to employees in occupations with higher job control. Exposure misclassification is inherent in the JEM as some individuals employed in job groups with high levels of job control have not actually experienced high job control and some individuals employed in job groups with low levels of job control have not actually experienced low job control. This misclassification is likely to result in an underestimation of the actual association between job control and depressive disorder. Two previous studies have investigated the association between job control 
and depressive disorder using aggregated exposure measures and results are inconclusive. One study [81] used a work-unit aggregated measure of job control and found statistically non-significant association between low levels of job control and risk of depressive disorder. Another [82] used a JEM and found no clear pattern in the association. Both studies emphasize the risk of exposure misclassification inherent in the aggregated exposure measure and attribute their lack of findings to this, and to healthy worker selection concurrently. Taken together, these studies suggest that although the use of aggregated measures of job control ensures that findings are not influenced by workers with pre-clinical depressive symptoms tending to see their work environment more negatively, results may be influenced by the problems inherited in the use of aggregated exposure measure such as a JEM. Following, results should be interpreted in light of the existing studies showing individual level associations between self-reported job control and depressive disorder [13, 14].

Additionally, despite its strengths, the clinically based outcome of depressive disorder may introduce bias with respect to SES [83]. Many depressive episodes remain untreated [84] or treated solely in primary care [85], and a recent study found, that individuals in higher levels of SES are more likely to receive treatment by a GP or a psychologist [86]. Therefore, it is possible that individuals in occupations with a high level of control (which are likely occupations with high SES) are more likely to receive treatment outside the hospital and therefore less often receive a hospital-based diagnosis of depressive disorder. Consequently, our findings should be interpreted with caution regarding higher levels of SES.

Acknowledgements The present study was funded by grants from the Danish Working Environment Research Fund (Grant Numbers 17-2014-03, 17-2014-03 and 43-2014-03) and Nordforsk (Grant Number 75021).

\section{Compliance with ethical standards}

Conflict of interest The authors declare that they have no conflict of interests.

Ethical standards According to Danish law, purely register-based research projects should not be notified to the national committee on health research ethics (http://en.nvk.dk/how-to-notify/what-to-notif y). The DAWCO project was registered with the Danish data protection agency under the blanket authorization of the Danish National Research Centre for the Working Environment and approved by the National Health Data Authority and Statistics Denmark.

Open Access This article is distributed under the terms of the Creative Commons Attribution 4.0 International License (http://creativeco mmons.org/licenses/by/4.0/), which permits unrestricted use, distribution, and reproduction in any medium, provided you give appropriate credit to the original author(s) and the source, provide a link to the Creative Commons license, and indicate if changes were made.

\section{References}

1. Wells KB, Stewart A, Hays RD, Burnam MA, Rogers W, Daniels M, Berry S, Greenfield S, Ware J (1989) The functioning and well-being of depressed patients: results from the medical outcomes study. JAMA 262(7):914-919

2. Alonso J, Angermeyer M, Bernert S, Bruffaerts R, Brugha T, Bryson H, de Girolamo G, de Graaf R, Demyttenaere K (2004) Prevalence of mental disorders in Europe: results from the European Study of the Epidemiology of Mental Disorders (ESEMeD) project. Acta Psychiatr Scand 109:21-27

3. Murray CJ, Lopez AD (1997) Alternative projections of mortality and disability by cause 1990-2020: global burden of disease study. Lancet 349(9064):1498-1504

4. Birnbaum HG, Kessler RC, Kelley D, Ben-Hamadi R, Joish VN, Greenberg PE (2010) Employer burden of mild, moderate, and severe major depressive disorder: mental health services utilization and costs, and work performance. Depress Anxiety 27(1):78-89

5. Ormel J, VonKorff M, Ustun TB, Pini S, Korten A, Oldehinkel T (1994) Common mental disorders and disability across cultures: results from the WHO Collaborative Study on Psychological Problems in General Health Care. JAMA 272(22):1741-1748

6. Martin J, Blum T, Beach S, Roman P (1996) Subclinical depression and performance at work. Soc Psychiatry Psychiatr Epidemiol 31(1):3-9

7. Bültmann U, Rugulies R, Lund T, Christensen KB, Labriola M, Burr H (2006) Depressive symptoms and the risk of longterm sickness absence. Soc Psychiatry Psychiatr Epidemiol 41(11):875-880

8. Kessler RC, Akiskal HS, Ames M, Birnbaum H, Greenberg P, Robert MA, Jin R, Merikangas KR, Simon GE, Wang PS (2006) Prevalence and effects of mood disorders on work performance in a nationally representative sample of US workers. Am J Psychiatry 163(9):1561-1568

9. Kendler KS, Gardner CO, Prescott CA (2006) Toward a comprehensive developmental model for major depression in men. Am J Psychiatry 163(1):115-124

10. Kendler KS, Gardner CO, Prescott CA (2005) Toward a comprehensive developmental model for major depression in women. Focus 159(1):1133-1197

11. Kendler KS, Gardner C (2016) Depressive vulnerability, stressful life events and episode onset of major depression: a longitudinal model. Psychol Med 46(9): 1865-1874

12. Köhler CA, Evangelou E, Stubbs B, Solmi M, Veronese N, Belbasis L, Bortolato B, Melo MC, Coelho CA, Fernandes BS (2018) Mapping risk factors for depression across the lifespan: An umbrella review of evidence from meta-analyses and Mendelian randomization studies. J Psychiatr Res 103:189-207

13. Madsen IE, Nyberg ST, Hanson LM, Ferrie JE, Ahola K, Alfredsson L, Batty GD, Bjorner JB, Borritz M, Burr H (2017) Job strain as a risk factor for clinical depression: systematic review and meta-analysis with additional individual participant data. Psychol Med 47(8):1342-1356

14. Theorell T, Hammarström A, Aronsson G, Bendz LT, Grape T, Hogstedt C, Marteinsdottir I, Skoog I, Hall C (2015) A systematic review including meta-analysis of work environment and depressive symptoms. BMC Public Health 15(1):738

15. Rugulies R, Aust B, Madsen IE (2017) Effort-reward imbalance at work and risk of depressive disorders. A systematic review and meta-analysis of prospective cohort studies. Scand J Work Environ Health 43(4):294-306

16. Karasek R (1979) Job demands, job decision latitude, and mental strain: Implications for job redesign. Adm Sci Q 24(2):285-308 
17. Karasek R, Theorell T (1990) Healthy work: stress, productivity and the reconstruction of working life. Basic Books, New York

18. Miller WR, Seligman ME (1975) Depression and learned helplessness in man. J Abnorm Psychol 84(3):228

19. Bandura A (1991) Self-efficacy mechanism in physiological activation and health-promoting nehavior. In: J M (ed) Neurobiology of learning, emotion and affect. Raven, New York, pp 229-270

20. Bandura A (1991) Self-regulation of motivation through anticipatory and self-reactive mechanisms. In: Perspectives on motivation: Nebraska symposium on motivation, pp 69-164

21. Wood R, Bandura A (1989) Social cognitive theory of organizational management. Acad Manag Rev 14(3):361-384

22. Bandura A (1986) Social foundations of thought and action. Englewood Cliffs, NJ, p 1986

23. Brown GW, Harris T (2012) Social origins of depression: a study of psychiatric disorder in women. Routledge, Abingdon

24. Brown GW, Harris TO (1989) Life events and illness. Guilford Press, New York

25. Lundberg O (1993) The impact of childhood living conditions on illness and mortality in adulthood. Soc Sci Med 36(8):1047-1052

26. Johnson JG, Cohen P, Dohrenwend BP, Link BG, Brook JS (1999) A longitudinal investigation of social causation and social selection processes involved in the association between socioeconomic status and psychiatric disorders. J Abnorm Psychol 108(3):490

27. Kessler RC, Magee WJ (1993) Childhood adversities and adult depression: basic patterns of association in a US national survey. Psychol Med 23(3):679-690

28. Gilman SE, Kawachi I, Fitzmaurice GM, Buka SL (2002) Socioeconomic status in childhood and the lifetime risk of major depression. Int J Epidemiol 31(2):359-367

29. Harvey SB, Sellahewa DA, Wang M-J, Milligan-Saville J, Bryan BT, Henderson M, Hatch SL, Mykletun A (2018) The role of job strain in understanding midlife common mental disorder: a national birth cohort study. Lancet Psychiatry 5(6):498-506

30. Madsen IE, Aust B, Burr H, Carneiro IG, Diderichsen F, Rugulies R (2012) Paid care work and depression: a longitudinal study of antidepressant treatment in female eldercare workers before and after entering their profession. Depress Anxiety 29(7):605-613

31. Smith PM, Bielecky A (2012) The impact of changes in job strain and its components on the risk of depression. Am J Public Health 102(2):352-358

32. Stansfeld SA, Clark C, Caldwell T, Rodgers B, Power C (2008) Psychosocial work characteristics and anxiety and depressive disorders in midlife: the effects of prior psychological distress. Occup Environ Med 65(9):634-642. https://doi.org/10.1136/ oem.2007.036640

33. Taris TW, Kompier MA (2014) Cause and effect: Optimizing the designs of longitudinal studies in occupational health psychology. Taylor \& Francis, London

34. Kolstad HA, Hansen ÅM, Kærgaard A, Thomsen JF, Kaerlev L, Mikkelsen S, Grynderup MB, Mors O, Rugulies R, Kristensen AS (2010) Job strain and the risk of depression: is reporting biased? Am J Epidemiol 173(1):94-102

35. Kivimäki M, Hotopf M, Henderson M (2010) Do stressful working conditions cause psychiatric disorders?. Oxford University Press, Oxford

36. Galobardes B, Lynch J, Smith GD (2007) Measuring socioeconomic position in health research. Br Med Bull 81(1):21

37. Galobardes B, Shaw M, Lawlor DA, Lynch JW, Smith GD (2006) Indicators of socioeconomic position (part 1). J Epidemiol Community Health 60(1):7-12

38. Galobardes B, Shaw M, Lawlor DA, Lynch JW, Smith GD (2006) Indicators of socioeconomic position (part 2). J Epidemiol Community Health 60(2):95-101
39. Madsen IESA, Holm A, Bonde JP, Burr H, Framke E, Melchior M, Rod NH, Sivertsen B, Stansfeld S, Sørensen JK, Virtanen M, Westerlund H, Rugulies R (2018) Study protocol for analyses on the prospective association of work-related violence, and decision latitude with risk of depression in The Danish Work Life Course Cohort. https://doi.org/10.6084/m9.figshare.6722852.v1

40. Petersson F, Baadsgaard M, Thygesen LC (2011) Danish registers on personal labour market affiliation. Scand J Public Health 39(7_suppl):95-98. https://doi.org/10.1177/1403494811408483

41. Alfredsson L, Karasek R, Theorell T (1982) Myocardial infarction risk and psychosocial work environment: an analysis of the male Swedish working force. Soc Sci Med 16(4):463-467

42. Solovieva S, Pensola T, Kausto J, Shiri R, Heliövaara M, Burdorf A, Husgafvel-Pursiainen K, Viikari-Juntura E (2014) Evaluation of the validity of job exposure matrix for psychosocial factors at work. PLoS One 9(9):e108987

43. Milner A, Niedhammer I, Chastang J-F, Spittal M, LaMontagne A (2016) Validity of a job-exposure matrix for psychosocial job stressors: results from the household income and labour dynamics in Australia survey. PLoS One 11(4):e0152980

44. Niedhammer I, Chastang J-F, Levy D, David S, Degioanni S, Theorell T (2008) Study of the validity of a job-exposure matrix for psychosocial work factors: results from the national French SUMER survey. Int Arch Occup Environ Health 82(1):87-97

45. Rijs KJ, van der Pas S, Geuskens GA, Cozijnsen R, Koppes LLJ, van der Beek AJ, Deeg DJH (2013) Development and validation of a physical and psychosocial job-exposure matrix in older and retired workers. Ann Occup Hyg 58(2):152-170

46. Boedeker W, Friedel H, Friedrichs M, Röttger C (2008) The impact of work on morbidity-related early retirement. J Public Health 16(2):97-105

47. Madsen IE, Gupta N, Budtz-Jørgensen E, Bonde JP, Framke E, Flachs EM, Petersen SB, Svane-Petersen AC, Holtermann A, Rugulies R (2018) Physical work demands and psychosocial working conditions as predictors of musculoskeletal pain: a cohort study comparing self-reported and job exposure matrix measurements. Occup Environ Med:oemed-2018

48. Feveile H, Olsen O, Burr H, Bach E (2007) Danish Work Environment Cohort Study 2005: from idea to sampling design. Stat Transit 8(3):441-458

49. Burr H, Bjorner JB, Kristensen TS, Tüchsen F, Bach E (2003) Trends in the Danish work environment in 1990-2000 and their associations with labor-force changes. Scand J Work Environ Health 24:270-279

50. Kristensen TS, Hannerz H, Høgh A, Borg V (2005) The Copenhagen psychosocial questionnaire-a tool for the assessment and improvement of the psychosocial work environment. Scand J Work Environ Health 31(6):438-449

51. Wikman A, Ørhede E (1988) Pilotprojekterne i Danmark og Sverige [The pilot projects in Denmark and Sweden]. Statistics Sweden, Stockholm

52. Mors O, Perto GP, Mortensen PB (2011) The Danish psychiatric central research register. Scand J Public Health 39(7_suppl):54-57

53. Lynge E, Sandegaard JL, Rebolj M (2011) The Danish national patient register. Scand J Public Health 39(7_suppl):30-33. https ://doi.org/10.1177/1403494811401482

54. Jensen VM, Rasmussen AW (2011) Danish education registers. Scand J Public Health 39(7_suppl):91-94. https://doi. org/10.1177/1403494810394715

55. Baadsgaard M, Quitzau J (2011) Danish registers on personal income and transfer payments. Scand J Public Health 39(7_ suppl):103-105. https://doi.org/10.1177/1403494811405098

56. Isced U (2012) International standard classification of education 2011. UNESCO Institute for Statistics Montreal, Canada 
57. Fahy A, Stansfeld S, Smuk M, Lain D, Van der Horst M, Vickerstaff S, Clark C (2017) Longitudinal associations of experiences of adversity and socioeconomic disadvantage during childhood with labour force participation and exit in later adulthood. Soc Sci Med 183:80-87

58. Pape K, Bjørngaard JH, Holmen TL, Krokstad S (2012) The welfare burden of adolescent anxiety and depression: a prospective study of 7500 young Norwegians and their families: the HUNT study. BMJ Open 2(6):e001942

59. Kjellberg K, Lundin A, Falkstedt D, Allebeck P, Hemmingsson T (2016) Long-term physical workload in middle age and disability pension in men and women: a follow-up study of Swedish cohorts. Int Arch Occup Environ Health 89(8):1239-1250

60. Lund RL, Klausen TB (2017) Lang vej at gå-social baggrund og studerendes alder på danske universiteter [A long way to go, social background and student age at Danish Universities]. Dansk Sociologi 27(2):9-34

61. Klausen TB (2016) Social origin and graduation age: a cohort comparison of Danish University Students. Scand J Educ Res 60(2):147-167

62. ILO (2013) Resolution concerning statistics of work, employment and labour underutilization: International Labour Organisation (ILO). http://www.ilo.org/global/statistics-and-databases/stand ards-and-guidelines/resolutions-adopted-by-international-confe rences-of-labour-statisticians/WCMS_230304/lang-en/index.htm. Accessed 2018

63. Guffanti G, Gameroff MJ, Warner V, Talati A, Glatt CE, Wickramaratne P, Weissman MM (2016) Heritability of major depressive and comorbid anxiety disorders in multi-generational families at high risk for depression. Am J Med Genet Part B Neuropsychiatr Genet 171(8):1072-1079

64. Fernandez-Pujals AM, Adams MJ, Thomson P, McKechanie AG, Blackwood DH, Smith BH, Dominiczak AF, Morris AD, Matthews K, Campbell A (2015) Epidemiology and heritability of major depressive disorder, stratified by age of onset, sex, and illness course in Generation Scotland: Scottish Family Health Study (GS: SFHS). PLoS One 10(11):e0142197

65. Mattejat F, Remschmidt H (2008) The children of mentally ill parents. Deutsches Ärzteblatt International 105(23):413

66. Stoeckel M, Weissbrod C (2015) Growing up with an ill parent: an examination of family characteristics and parental illness features. Fam Syst Health 33(4):356

67. Higgins KS, Birnie KA, Chambers CT, Wilson AC, Caes L, Clark AJ, Lynch M, Stinson J, Campbell-Yeo M (2015) Offspring of parents with chronic pain: a systematic review and meta-analysis of pain, health, psychological, and family outcomes. Pain 156(11):2256

68. Wray NR, Gottesman II (2012) Using summary data from the danish national registers to estimate heritabilities for schizophrenia, bipolar disorder, and major depressive disorder. Front Genet 3:118. https://doi.org/10.3389/fgene.2012.00118

69. Canário C, Figueiredo B (2017) Anxiety and depressive symptoms in women and men from early pregnancy to 30 months postpartum. J Reprod Infant Psychol 35(5):431-449

70. Pedersen CB (2011) The Danish civil registration system. Scand J Public Health 39(7_suppl):22-25. https://doi.org/10.1177/14034 94810387965

71. Therneau T, Crowson C, Atkinson E (2013) Using time dependent covariates and time dependent coefficients in the cox model. Red $2: 1$

72. Johnson JV, Stewart W, Hall EM, Fredlund P, Theorell T (1996) Long-term psychosocial work environment and cardiovascular mortality among Swedish men. Am J Public Health 86(3):324-331

73. Theorell T, De Manzano Ö, Lennartsson AK, Pedersen NL, Ullén F (2016) Self-reported psychological demands, skill discretion and decision authority at work: a twin study. Scand J Public Health 44(4):354-360. https://doi.org/10.1177/1403494815626610

74. Van Laethem M, Beckers DG, Kompier MA, Dijksterhuis A, Geurts SA (2013) Psychosocial work characteristics and sleep quality: a systematic review of longitudinal and intervention research. Scand J Work Environ Health 39(6):535-549. https:// doi.org/10.5271/sjweh.3376

75. Egan M, Bambra C, Thomas S, Petticrew M, Whitehead M, Thomson H (2007) The psychosocial and health effects of workplace reorganisation. 1. A systematic review of organisationallevel interventions that aim to increase employee control. J Epidemiol Community Health 61(11):945-954. https://doi.org/10.1136/ jech.2006.054965

76. Bambra C, Egan M, Thomas S, Petticrew M, Whitehead M (2007) The psychosocial and health effects of workplace reorganisation. 2. A systematic review of task restructuring interventions. J Epidemiol Community Health 61(12):1028-1037. https://doi. org/10.1136/jech.2006.054999

77. Williams-Whitt K, White MI, Wagner SL, Schultz IZ, Koehn C, Dionne CE, Koehoorn M, Harder H, Pasca R, Warje O, Hsu V, McGuire L, Schulz W, Kube D, Hook A, Wright MD (2015) Job demand and control interventions: a stakeholder-centered bestevidence synthesis of systematic reviews on workplace disability. Int J Occup Environ Med 6(2):61-78. https://doi.org/10.15171/ ijoem. 2015.553

78. Niedhammer I (2002) Psychometric properties of the French version of the Karasek Job Content Questionnaire: a study of the scales of decision latitude, psychological demands, social support, and physical demands in the GAZEL cohort. Int Arch Occup Environ Health 75(3):129-144

79. Karasek R, Brisson C, Kawakami N, Houtman I, Bongers P, Amick B (1998) The Job Content Questionnaire (JCQ): an instrument for internationally comparative assessments of psychosocial job characteristics. J Occup Health Psychol 3(4):322

80. Stiglbauer B, Kovacs C (2017) The more, the better? Curvilinear effects of job autonomy on well-being from vitamin model and PE-fit theory perspectives

81. Grynderup MB, Mors O, Hansen ÅM, Andersen JH, Bonde JP, Kærgaard A, Kærlev L, Mikkelsen S, Rugulies R, Thomsen JF (2012) A two-year follow-up study of risk of depression according to work-unit measures of psychological demands and decision latitude. Scand J Work Environ Health 527-536

82. Wieclaw J, Agerbo E, Mortensen PB, Burr H, Tuchsen F, Bonde JP (2008) Psychosocial working conditions and the risk of depression and anxiety disorders in the Danish workforce. BMC Public Health 8(1):280

83. Thielen K, Nygaard E, Andersen I, Rugulies R, Heinesen E, Bech P, Bültmann U, Diderichsen F (2009) Misclassification and the use of register-based indicators for depression. Acta Psychiatr Scand 119(4):312-319. https://doi.org/10.1111/j.1600-0447.2008.01282.x

84. Wittchen HU, Jacobi F (2005) Size and burden of mental disorders in Europe - a critical review and appraisal of 27 studies. Eur Neuropsychopharmacol 15(4):357-376. https://doi.org/10.1016/j. euroneuro.2005.04.012

85. Alonso J, Angermeyer M, Bernert S, Bruffaerts R, Brugha T, Bryson H, de Girolamo G, de Graaf R, Demyttenaere K (2004) Use of mental health services in Europe: results from the European Study of the Epidemiology of Mental Disorders (ESEMeD) project. Acta Psychiatr Scand 109:47-54

86. Packness A, Waldorff FB, dePont Christensen R, Hastrup LH, Simonsen E, Vestergaard M, Halling A (2017) Impact of socioeconomic position and distance on mental health care utilization: a nationwide Danish follow-up study. Soc Psychiatry Psychiatr Epidemiol 52(11):1405-1413. https://doi.org/10.1007/s0012 7-017-1437-2 